SOUZA, Matheus Figueiredo Nunes de. Direito, Estado e Democracia em Tempos de Globalização. Revista Eletrônica Direito e Política, Programa de Pós-Graduação Stricto Sensu em Ciência Jurídica da UNIVALI, Itajaí, v.12, n.3, 30 quadrimestre de 2017. Disponível em: www.univali.br/direitoepolitica - ISSN 1980-7791

\title{
DIREITO, ESTADO E DEMOCRACIA EM TEMPOS DE GLOBALIZAÇÃO
}

\author{
LAW, STATE AND DEMOCRACY IN TIMES OF GLOBALIZATION
}

\section{Matheus Figueiredo Nunes de Souza'}

SUMÁRIO: Introdução; 10 Direito para tempos de globalização; 1.1 A quebra da centralidade normativa: o Direito para além do Estado; 2 O Estado e a Constituição para a Contemporaneidade; 2.1 Teoria do Estado de Hermann Heller; 2.2 A Teoria do Estado e da Constituição por Jorge Miranda; 2.3 Teoria da Interconstitucionalidade; 3 A democracia na era da globalização; Considerações finais; Referências das fontes citadas

\section{RESUMO}

O tema do presente trabalho são as interações entre Direito, Estado e Democracia em tempos de globalização. O objetivo geral almejado é verificar como as bases clássicas do Estado se apresentam face à globalização. O método de pesquisa utilizado foi o dedutivo, utilizando-se das técnicas de pesquisa de consulta bibliográfica, para embasamento teórico; e fichamentos. As considerações finais obtidas através desta pesquisa são no sentido da existência de uma democracia participativa que almeja a transparência como pretensão jurídica global, permitindo os vários jogos de diálogo entre os diversos ordenamentos jurídicos.

PALAVRAS-CHAVE: Policontexturalidade; Estado; Democracia; Globalização

\begin{abstract}
The theme of the present work is the interactions between Law, State and Democracy in times of globalization. The general objective is to verify how the classic bases of the State present themselves in the face of globalization. The method of research used was the deductive, using the techniques of research of bibliographical consultation, for theoretical foundation; and book reports. The final considerations obtained through this research are in the sense of the existence of a participatory democracy that aims at transparency as a global legal claim, allowing the various games of dialogue between the different legal systems.
\end{abstract}

KEYWORDS: Polycontexturality; State; Democracy; Globalization

\footnotetext{
1 Mestrando em Direito pela Faculdade Meridional - IMED. Bolsista CAPES/PROSUP. Pesquisador no Grupo de Pesquisa Ética, Cidadania e Sustentabilidade, da Faculdade Meridional - IMED, atuando nos seguintes temas: Teoria dos Sistemas Autopoiéticos; Sociologia Jurídica; Teoria Constitucional e Teoria Geral do Estado; e Direito Constitucional. Passo Fundo. RS. Brasil. Currículo Lattes: http://lattes.cnpq.br/2439297883147393 - E-mail: matheus.nunnes13@gmail.com.
} 
SOUZA, Matheus Figueiredo Nunes de. Direito, Estado e Democracia em Tempos de Globalização. Revista Eletrônica Direito e Política, Programa de Pós-Graduação Stricto Sensu em Ciência Jurídica da UNIVALI, Itajaí, v.12, n.3, 30 quadrimestre de 2017. Disponível em: www.univali.br/direitoepolitica - ISSN 1980-7791

\section{INTRODUÇÃO}

O presente artigo tem como objetivo geral debater sobre a situação do Direito, do Estado e da Democracia em tempos de globalização. Assim, com o intento de cumprir com tal pretensão, primeiramente far-se-á uma análise a partir do Direito em tempos de globalização, apontando para uma desconstrução da hierarquia do Direito - uma quebra da centralidade de produção normativa; em um segundo instante, far-se-á a análise do Estado e sua Constituição frente à contemporaneidade, realizando uma investigação a partir da Teoria do Estado de Hermann Heller, da Teoria do Estado e da Constituição de Jorge Miranda e da Teoria da Interconstitucionalidade de Canotilho. Por último, far-se-á um estudo sobre a Democracia em um panorama de globalização e transnacionalismo, questionando se as concepções voltadas para uma visão nacional podem sobreviver às incursões de elementos externos.

O problema de pesquisa a ser levantado neste trabalho é: como trabalhar com contextos de produção normativa descentralizados face ao Direito, Estado e Democracia em tempos de globalização? O motivo pelo qual se procedeu a esta investigação é a necessidade de pensar estes três elementos: o Direito, o Estado e a Democracia, de forma diferente, pois o Estado há muito perdeu seu protagonismo, passando a ser visto como um simples herói do local. Assim sendo, o direito estatal também deixou de ser o único centro de produção normativa, permitindo que os discursos jurídicos advindos de contextos sociais também pudessem ser observados. Em virtude disso, a Democracia, em suas concepções mais tradicionais, deixa de responder aos anseios da sociedade, impondo-se uma remodelação para a compreensão do seu papel nos dias atuais.

O método de pesquisa utilizado foi o dedutivo, valendo-se das técnicas de pesquisa de consulta bibliográfica, para o referencial teórico; e fichamentos. Ademais, a hipótese levantada é que nem o Direito, o Estado e a Democracia conseguem lidar com as incursões externas, necessitando se adaptar aos fluxos globalizatórios.

Assim sendo, em um panorama global, observa-se um fenômeno policontextural na produção do direito; o Estado passa a ser poroso, em contraposição aos 
SOUZA, Matheus Figueiredo Nunes de. Direito, Estado e Democracia em Tempos de Globalização. Revista Eletrônica Direito e Política, Programa de Pós-Graduação Stricto Sensu em Ciência Jurídica da UNIVALI, Itajaí, v.12, n.3, 30 quadrimestre de 2017. Disponível em: www.univali.br/direitoepolitica - ISSN 1980-7791

modelos constitucionalmente fechados; a Constituição deixa de ser o topo da pirâmide e a Democracia clama por uma "partilha do poder" com a emergência de novos atores, através da participação e almejando a transparência como pretensão jurídica global.

\section{O DIREITO PARA TEMPOS DE GLOBALIZAÇÃo}

Nas últimas décadas têm-se verificado a intensificação do processo de globalização, com destaque na década de 1990, principalmente após a queda do Muro de Berlim, que fez com que o dualismo entre Capitalismo x Socialismo cessasse.

Em virtude deste fato histórico, a integração da sociedade aumentou, promovendo relações de múltiplos níveis nos mais variados âmbitos sociais. O primeiro contexto a se verificar estas interações foi no campo econômico - a Cortina de Ferro agora era derrubada, sendo de fácil visualização as relações entre países capitalistas da Europa Ocidental com os antigos Estados-membros da União das Repúblicas Socialistas Soviéticas (URSS), à Europa Oriental.

Assim, com a emergência de uma realidade até o momento estranha, as estruturas sociais tiveram que se adequar, fazendo com que o Direito, também, buscasse sua explicação no novo paradigma.

Devido a estes fatores, a compreensão do Direito através de um prisma positivista normativista ${ }^{2}$ (onde a norma é produzida por um ato de vontade, e estas se encontram escalonadas, sempre buscando o fundamento de validade em uma norma superior) ou pela ótica de um positivismo inclusivista ${ }^{3}$ (onde o direito seria nada mais que um conjunto de regras primárias e secundárias utilizado pela comunidade, com uma forte carga moral) não eram mais adequadas para os dias atuais.

\footnotetext{
2 KELSEN, Hans. Teoria Pura do Direito. Tradução: João Baptista Machado. 6. ed. São Paulo: Martins Fontes, 1998.

3 HART, H. L. A. O Conceito de Direito. Tradução: A. Ribeiro Mendes. 3. ed. Lisboa: Fundação Calouste Gulbenkian, 2001, p. 91.
} 
SOUZA, Matheus Figueiredo Nunes de. Direito, Estado e Democracia em Tempos de Globalização. Revista Eletrônica Direito e Política, Programa de Pós-Graduação Stricto Sensu em Ciência Jurídica da UNIVALI, Itajaí, v.12, n.3, 30 quadrimestre de 2017. Disponível em: www.univali.br/direitoepolitica - ISSN 1980-7791

A era da globalização fez com que os Estados nacionais deixassem de ser os senhores dominantes e acabassem perdendo parte de seu protagonismo em detrimento do surgimento de novos atores.

Isso acabou refletindo na necessidade de desconstrução da hierarquia do direito para tempos de descentralização normativa, tendo que as consequências não se limitam apenas a um contexto, ultrapassando qualquer fronteira imposta pelo Estado.

Com a globalização adentrou-se em uma era de interdependência, comunicação e pluralismo normativo. A falência dos modelos constitucionais fechados é iminente e sua morte é anunciada.

Assim sendo, buscou-se auxilio nos ensinamentos de Gunther Teubner a fim de explicar o fenômeno da "policontexturalidade" normativa, que diz respeito às diversas formas de produção do Direito através de contextos sociais, onde o Estado deixa de ser o único centro de produção normativa, permitindo observações e dando voz aos plúrimos discursos jurídicos na Sociedade.

\subsection{A QUEBRA DA CENTRALIDADE NORMATIVA: O DIREITO PARA ALÉM DO ESTADO}

Frente à complexidade das interações inerentes de uma sociedade global, bem como a multiplicidade de ordenamentos jurídicos entrelaçados, a simples apreciação das prescrições legais estatais limita as possibilidades de observação. Por esse motivo, é imperioso que, além da leitura da lei e sua interpretação, se faça uma leitura jus-sociológica acerca da efetividade do Direito.

Ao se partir dessa perspectiva, verifica-se que muitas vezes o "direito do Estado" não chega a uma determinada localidade, ou, ainda que chegue, não possui efetividade prática, haja vista que as tradições e a cultura de determinada comunidade não considerem correta tal aplicação. 
SOUZA, Matheus Figueiredo Nunes de. Direito, Estado e Democracia em Tempos de Globalização. Revista Eletrônica Direito e Política, Programa de Pós-Graduação Stricto Sensu em Ciência Jurídica da UNIVALI, Itajaí, v.12, n.3, 30 quadrimestre de 2017. Disponível em: www.univali.br/direitoepolitica - ISSN 1980-7791

Com o intento de ilustrar tal situação, Teubner ${ }^{4}$ trabalha a Crônica de uma Morte Anunciada, de Gabriel Garcia Marquez, para tratar da eficácia empírica das normas existentes. No conto, um vilarejo na costa caribenha da Colombia, festejava-se um grande casamento. Entretanto, na noite de núpcias, a moça, Ângela Vicário, foi devolvida à casa dos pais, pois o noivo havia percebido que a mesma não era mais virgem. Na comunidade havia uma norma social que previa a morte para quem deflorasse uma jovem antes do casamento. Todos na vila sabiam quem cometera o ato, porém, ninguém entregou o rapaz, pois não concordavam com a referida norma.

Diante disso, percebe-se a crescente crise regulatória do Direito, no qual ocorrem colisões acerca de qual parâmetro normativo é necessário se orientar.

A partir de uma análise desse romance, Teubner começa a se questionar como ocorre a atuação das normas na Sociedade, e se são eficazes ou não ${ }^{5}$. Assim, partindo de uma análise jurídica, questiona-se: de que forma uma norma estatal não é aceita pela sociedade?

Dessa forma, Luhmann explica que nenhuma auto-observação tem condições de entender a plena realidade, ${ }^{6}$ pois a complexidade e as interações a nível global são contingenciais, criando assim, um ponto cego que somente poderá ser visto pelo outro.

Frente à diversidade de Estados, cada um toma para si seu ordenamento jurídico como o único correto e que deve ser seguido, acabando por negar o alter de alguma forma. Ademais, existem várias ordens jurídicas além-Estado, como aquelas estabelecidas por Organizações Internacionais (ONU, OMC) e aquelas existentes em blocos regionais (União Europeia, MERCOSUL).

4 TEUBNER, Gunther. Direito, Sistema e Policontexturalidade. Tradução: Jürgen Volker Dittbrener... (et. al.). Piracicaba: editora Unimep, 2005, p. 21.

5 TONET, Fernando. Reconfigurações do Constitucionalismo: evolução e modelos constitucionais sistêmicos na pós-modernidade. Rio de Janeiro, Lumen Juris, 2013, p. 168.

6 LUHMANN, Niklas. La sociedad de La sociedad. Traducción: Javier Torres Nafarrate. Ciudad de México: edición Heder, 2006, p. 62. 
SOUZA, Matheus Figueiredo Nunes de. Direito, Estado e Democracia em Tempos de Globalização. Revista Eletrônica Direito e Política, Programa de Pós-Graduação Stricto Sensu em Ciência Jurídica da UNIVALI, Itajaí, v.12, n.3, 30 quadrimestre de 2017. Disponível em: www.univali.br/direitoepolitica - ISSN 1980-7791

A utilização da expressão "policontextos"/"policontexturalidade" não é em vão, pois se trata justamente de uma releitura da teoria do Pluralismo Jurídico nas suas várias perspectivas (econômica, jurídica, social, entre outras).

Nessa perspectiva, Teubner afirma que são nas normas informais das culturas políticas alternativas, no "quase-direito" das favelas do Brasil, nas técnicas disciplinares da "justiça privada" e nos regulamentos internos de organizações formais e redes informais que se encontram o local, o plural, o subversivo... $\mathrm{O}$ direito passa a ser uma diversidade de discursos fragmentados que pode ser identificado em diversos tipos informais de regras e que surgem quase independentemente do Estado. ${ }^{7}$

Para tanto, o citado autor aduz que o caso mais bem sucedido de lei sem Estado tem sido a Lex mercatoria, que se traduz em uma ordem transnacional de mercados globais que têm se desenvolvido fora do âmbito das leis nacionais e internacionais. Empresas multinacionais formam contratos em que não se submetem nem à legislação ou jurisdição nacionais, recorrendo à arbitragem internacional e à aplicação de uma lei comercial transnacional. ${ }^{8}$

Nesse mesmo sentido Staffen explica que entes particulares adotam normas que estão além do mero circulo do território nacional, mas que podem vir a causar influências em ordenamentos jurídicos de outros Estados e/ou organizações. É entre o direito nacional e internacional que o aspecto de transnacionalidade se situa. ${ }^{9}$

A fim de explicitar o conceito de direito transnacional, Craig Scott propõe três concepções, dentre as quais a terceira nos parece mais adequada (pluralismo sócio-legal transnacional), pois é aqui que se verifica, efetivamente, o direito transnacional como algo autônomo - em virtude de certa "marginalidade" da lei,

7 TEUBNER, Gunther. Direito, Sistema e Policontexturalidade. Tradução: Jürgen Volker Dittbrener et. al. Piracicaba: Editora da Unimep, 2005, p. 81.

8 TEUBNER, Gunther. The King's Many Bodies: The Self-Deconstruction of Law's Hierarchy. Law and Society Review. Volume 31, Number 4, 1997, p. 769.

9 STAFFEN, Márcio Ricardo. Direito Global: Humanismo e Direitos Humanos. RVMD, Brasília, v. 10, no 1, Jan-Jun., 2016, p. 181. 
SOUZA, Matheus Figueiredo Nunes de. Direito, Estado e Democracia em Tempos de Globalização. Revista Eletrônica Direito e Política, Programa de Pós-Graduação Stricto Sensu em Ciência Jurídica da UNIVALI, Itajaí, v.12, n.3, 30 quadrimestre de 2017. Disponível em: www.univali.br/direitoepolitica - ISSN 1980-7791

que não está enraizada nem no Estado nem no direito interestatal, onde o autor apresenta diversos exemplos que ilustram tal concepção. ${ }^{10}$

Tendo em vista que a sociedade tornou-se plural, os modelos constitucionais cerrados devem ser repensados de maneira crítica, pois em virtude do caráter multicultural, acabam carecendo de estruturas teóricas para se desenvolverem em um processo integrativo.

Diante disso, a (nova) dimensão global do Direito não visa acabar com o Estado e seu espaço de governo, muito embora os conceitos clássicos de Estado e Constituição sejam insuficientes para responder às interações civilizacionais contemporâneas, pois no plano fático existe uma verdadeira impossibilidade de separar-se o nacional do internacional.

Assim, a melhor forma de encarar a situação contemporânea é promovendo uma mudança no modo tradicional de pensar as instituições para um "contexto de conectividade horizontal dos sistemas jurídicos, criando linkages, paradigma este suportado pela credibilidade em rede, verdadeiro regime complex". ${ }^{11}$

\section{ESTADO E A CONSTITUIÇÃO PARA A CONTEMPORANEIDADE}

Conforme explica Abbagnano em seu Dicionário de Filosofia, o Estado, em geral, é uma organização jurídica coercitiva de determinada comunidade. Segundo explica, existem três concepções fundamentais: (1) a organicista; (2) a contratualista e; (3) a formalista. As duas primeiras se alternaram em diversos

\footnotetext{
10 A primeira concepção levantada pelo autor é que se trata de um "Tradicionalismo Jurídico Transnacionalizado", focado em um contexto empírico - algumas vezes atraindo, outras evitando a regulação. O foco é voltado para a primeira sentença de Jessup ao tentar enquadrar "direito transnacional" dizendo que se trata de toda lei que regula ações ou eventos que transcendem fronteiras nacionais. Já a segunda concepção trabalhada por Scott admitiria que o Tradicionalismo Jurídico pode estar certo ao dizer que o "direito", ao lidar com fenômenos transnacionais, pode sempre, em alguns aspectos, ser analiticamente traçado de um para mais sistemas legais e/ou direito internacional público. Ver SCOTT, Craig. "Transnational" Law as a Proto-concept: Three Conceptions. CLPE Research Paper 33/2009. vol. 05, nº. 06, p. 868-875.

11 STAFFEN, Márcio Ricardo; ZAMBAM, Neuro. Direito Global e Desigualdades: Um Estudo a partir do "Direito dos Povos" de John Rawls. Revista Eletrônica do Curso de Direito da UfSM. v. 10, n. 1, 2015, p. 253.
} 
SOUZA, Matheus Figueiredo Nunes de. Direito, Estado e Democracia em Tempos de Globalização. Revista Eletrônica Direito e Política, Programa de Pós-Graduação Stricto Sensu em Ciência Jurídica da UNIVALI, Itajaí, v.12, n.3, 30 quadrimestre de 2017. Disponível em: www.univali.br/direitoepolitica - ISSN 1980-7791

períodos históricos e a última, segundo a qual o Estado é uma formação jurídica, é de caráter moderno. ${ }^{12}$

As concepções organicista e contratualista têm em comum o reconhecimento do caráter sociológico do Estado, ou seja, é considerado em primeiro instante como comunidade - um grupo social que reside em certo território (o que foi a base para a fundamentação de que o Estado tem três elementos: soberania, povo e território). ${ }^{13}$

No entanto, este caráter vai vir a ser negado por Kelsen, em virtude de seu formalismo, ao dizer que é mais correto definir o Estado como "organização política". Por ser uma organização é uma ordem, e seu caráter político reside em sua coercitividade. Conforme explica o citado autor, o Estado "é uma organização política por ser uma ordem que regula o uso da força, porque ela monopoliza o uso da força". ${ }^{14}$

Ocorre que estas concepções apresentadas, embora muito esclarecedoras, ainda não satisfazem todos os aspectos que são necessários para a compreensão do Estado na contemporaneidade.

Pensando nisso, Bobbio, Matteucci e Pasquino vão expor em seu Dicionário de Política uma explicação acerca do Estado Contemporâneo, que parece ajustada. Conforme salienta, a própria definição de "Estado Contemporâneo" sofre problemas em virtude da complexidade, dificuldade em analisar as múltiplas relações que se criaram entre Estado e o complexo social e de captar os seus efeitos sobre a racionalidade interna do sistema político ${ }^{15}$.

12 ABBAGNANO, Nicola. Dicionário de Filosofia. Tradução da $1^{0}$ edição brasileira coordenada e revista por Alfredo Bossi; revisão da tradução e tradução dos novos textos Ivone Castilho Benedetti. 5. ed. São Paulo: Martins Fontes, 2007, p. 364.

13 ABBAGNANO, Nicola. Dicionário de Filosofia. Tradução da $1^{0}$ edição brasileira coordenada e revista por Alfredo Bossi; revisão da tradução e tradução dos novos textos Ivone Castilho Benedetti. 5. ed. São Paulo: Martins Fontes, 2007, p. 365.

14 KELSEN, Hans. Teoria Geral do Direito e do Estado. Tradução de Luís Carlos Borges. 3. ed. São Paulo: Martins Fontes, 1998, p. 273.

15 BOBBIO, Norberto; MATTEUCCI, Nicola; PASQUINO, Gianfranco. Dicionário de Política. Tradução Carmen C. Varriale et. al.; coordenação da tradução João Ferreira; revisão geral João 
SOUZA, Matheus Figueiredo Nunes de. Direito, Estado e Democracia em Tempos de Globalização. Revista Eletrônica Direito e Política, Programa de Pós-Graduação Stricto Sensu em Ciência Jurídica da UNIVALI, Itajaí, v.12, n.3, 30 quadrimestre de 2017. Disponível em: www.univali.br/direitoepolitica - ISSN 1980-7791

Uma abordagem útil para a compreensão do desenvolvimento do Estado Contemporâneo é a análise da difícil coexistência das formas de Estado de Direito com os conteúdos do Estado Social. Neste sentido, aquele traz consigo os direitos fundamentais, que representam a tutela das liberdades burguesas, enquanto este traz os direitos sociais, que representam os direitos de participação no poder político e na distribuição da riqueza social produzida - e também a via por onde a sociedade entra no Estado, modificando-Ihe a estrutura forma. Assim, a forma do Estado oscila entre a liberdade e a participação. ${ }^{16}$

Partindo-se da ciência do(s) conceito(s) de Estado, agora é necessário fazer uma abordagem acerca da Teoria que lhe submete como objeto. Far-se-á uma (breve) análise (dos pontos relevantes) da Teoria do Estado de Hermann Heller; das proposições teóricas acerca do Estado e da Constituição feitas por Jorge Miranda e, por último; da Teoria da Interconstitucionalidade de Gomes Canotilho.

\subsection{TEORIA DO ESTADO DE HERMANN HELLER}

Em um primeiro momento, Hermann Heller vai explicar que a Teoria do Estado se propõe a investigar a realidade específica da vida estatal que nos rodeia compreender o Estado em sua função e estrutura atuais, o devir histórico e as tendências de sua evolução. ${ }^{17}$

Ao tratar especificamente as questões diretamente relacionadas ao Estado, Heller inicia pelas condições geográficas da atividade estatal, explicando que a atividade do Estado não depende, nunca, de forma unilateral, de quaisquer leis estáticas da Geografia - pois a terra apenas é uma condição. Portanto, o Estado

Ferreira e Luis Guerreiro Pinto Cacais. 1. ed. Brasília: Editora Universidade de Brasília, 1998, p. 401.

16 BOBBIO, Norberto; MATTEUCCI, Nicola; PASQUINO, Gianfranco. Dicionário de Política. Tradução Carmen C. Varriale et. al.; coord. trad. João Ferreira; rev. geral João Ferreira e Luis Guerreiro Pinto Cacais. 1. ed. Brasília: Editora Universidade de Brasília, 1998, p. 401.

17 HELLER, Hermann. Teoria do Estado. Tradução: Lycurgo Gomes da Motta. Supervisão: João Mendes de Almeida. 1. ed. São Paulo: Editora Mestre Jou, 1968, p. 21. 
SOUZA, Matheus Figueiredo Nunes de. Direito, Estado e Democracia em Tempos de Globalização. Revista Eletrônica Direito e Política, Programa de Pós-Graduação Stricto Sensu em Ciência Jurídica da UNIVALI, Itajaí, v.12, n.3, 30 quadrimestre de 2017. Disponível em: www.univali.br/direitoepolitica - ISSN 1980-7791

nunca deve ser um "escravo" de seu território - não deve limitar-se a este "corpo". 18

Consoante o jurista e teórico político alemão, não é natureza que vai determinar as fronteiras políticas da individualidade estatal, mas sim as ações do Estado dessa forma, as fronteiras políticas seriam limites queridos pelos homens e nascidos das relações de poder. ${ }^{19}$

Avançando em suas proposições sobre as condições da atividade estatal, Heller agora adentra no aspecto que se relaciona com o povo, frisando que a ideia de "povo" enquanto uma comunidade originária de um tronco racial, ou enquanto população (em seu aspecto natural) não se encaixam mais para os anseios teóricos, sendo necessário pensar o "povo" enquanto cultural, que é politicamente amorfo, mas que se transforma em nação quando a consciência de pertencer ao conjunto chega a se transformar em uma ligação de vontade política. ${ }^{20}$

O autor também vai destacar acerca da unidade estatal, afirmando que esta unidade é de ação humana organizada ${ }^{21}$ de natureza especial. Assim, o Estado diferencia-se de todos os outros grupos territoriais de dominação por seu caráter de soberania de ação e decisão, sendo que todas as unidades de poder que existem em seu território podem aplicar o poder físico coativo e executar suas decisões. ${ }^{22}$

O poder do Estado pode ser visto tanto como unidade de ação política quanto de decisão política. Primeiramente, a essência do poder (social) do Estado, como

18 HELLER, Hermann. Teoria do Estado. Tradução: Lycurgo Gomes da Motta. Supervisão: João Mendes de Almeida. 1. ed. São Paulo: Editora Mestre Jou, 1968, p. 177/178.

19 HELLER, Hermann. Teoria do Estado. Tradução: Lycurgo Gomes da Motta. Supervisão: João Mendes de Almeida. 1. ed. São Paulo: Editora Mestre Jou, 1968, p. 179.

20 HELLER, Hermann. Teoria do Estado. Tradução: Lycurgo Gomes da Motta. Supervisão: João Mendes de Almeida. 1. ed. São Paulo: Editora Mestre Jou, 1968, p. 195/197.

21 Organização é um trabalho destinado a realizar aquelas ações (ou omissões) necessárias à existência atual e constantemente renovada de uma estrutura efetiva ordenada. Ver HELLER, Hermann. Teoria do Estado. Tradução: Lycurgo Gomes da Motta. Supervisão: João Mendes de Almeida. 1. ed. São Paulo: Editora Mestre Jou, 1968, p. 275.

22 HELLER, Hermann. Teoria do Estado. Tradução: Lycurgo Gomes da Motta. Supervisão: João Mendes de Almeida. 1. ed. São Paulo: Editora Mestre Jou, 1968, p. 281. 
SOUZA, Matheus Figueiredo Nunes de. Direito, Estado e Democracia em Tempos de Globalização. Revista Eletrônica Direito e Política, Programa de Pós-Graduação Stricto Sensu em Ciência Jurídica da UNIVALI, Itajaí, v.12, n.3, 30 quadrimestre de 2017. Disponível em: www.univali.br/direitoepolitica - ISSN 1980-7791

unidade de ação, pode ser explicado causalmente pela cooperação de todos os membros, sofre influência das gerações passadas e é produto (também) das forças que atuam de fora sobre essa organização. ${ }^{23}$ Enquanto unidade de decisão política, percebe-se essencial importância na questão dos sujeitos de decisão, que são aqueles que, no caso concreto, aplicam e atualizam o poder da organização e concretizam em uma atividade individual o poder pela acumulação de atividades particulares. ${ }^{24}$

Tudo isso torna-se possível a partir da perspectiva de que o Direito ${ }^{25}$ é condição possibilitadora da unidade estatal. Heller explica que, partindo do fato de que o direito é aquela ordenação normativa social estabelecida e garantida pelos órgãos da organização estatal, percebe-se uma correlativa vinculação (entre Estado e Direito). É necessário superar a oposição entre natureza e espírito, ato e sentido, vontade e norma - e isto só pode acontecer a partir da consideração de que o dever ser jurídico é, ao mesmo tempo, um querer humano, que enquanto ato criador de direito, há de conter já uma exigência ou uma norma. ${ }^{26}$

Por fim, destaca a Constituição do Estado. Heller conseguiu integrar as concepções sociológica e política com a normativa. Segundo explica, a Constituição estatal é a Constituição política da realidade social, pois ela "coincide com a sua organização enquanto esta significa a constituição produzida mediante atividade humana consciente". ${ }^{27}$ No conceito de Constituição, não há como ter uma separação entre ser (normalidade) e dever-ser (normatividade) -

${ }^{23}$ HELLER, Hermann. Teoria do Estado. Tradução: Lycurgo Gomes da Motta. Supervisão: João Mendes de Almeida. 1. ed. São Paulo: Editora Mestre Jou, 1968, p. 283/284.

24 HELLER, Hermann. Teoria do Estado. Tradução: Lycurgo Gomes da Motta. Supervisão: João Mendes de Almeida. 1. ed. São Paulo: Editora Mestre Jou, 1968, p. 291.

25 Conforme explica Heller, o termo "Direito" a que se refere, diz respeito apenas ao direito positivo, que é o único a que se pode referir a Teoria do Estado.

26 HELLER, Hermann. Teoria do Estado. Tradução: Lycurgo Gomes da Motta. Supervisão: João Mendes de Almeida. 1. ed. São Paulo: Editora Mestre Jou, 1968, p. 228/229.

27 HELLER, Hermann. Teoria do Estado. Tradução: Lycurgo Gomes da Motta. Supervisão: João Mendes de Almeida. 1. ed. São Paulo: Editora Mestre Jou, 1968, p. 295. 
SOUZA, Matheus Figueiredo Nunes de. Direito, Estado e Democracia em Tempos de Globalização. Revista Eletrônica Direito e Política, Programa de Pós-Graduação Stricto Sensu em Ciência Jurídica da UNIVALI, Itajaí, v.12, n.3, 30 quadrimestre de 2017. Disponível em: www.univali.br/direitoepolitica - ISSN 1980-7791

a Constituição "não normada" e "normada" são duas faces de uma "Constituição total". ${ }^{28}$

Diante do exposto, verifica-se que as proposições de Hermann Heller estão direcionadas à Política (enquanto ciência), onde faz abordagens acerca dos (clássicos) conceitos de povo, território e soberania/governo. Para o teórico político alemão, o povo não é mais visto como população, mas passa a ter uma conotação de nação no momento de uma identificação cultural; o território, que antes era limitado apenas à concepção natural (superfície terrestre), ganhar contornos de geografia política, onde suas fronteiras são estabelecidas através de relações de poder; e a soberania do Estado se expressa em sua unidade enquanto decisão e ação, tudo isso tendo o Direito como condição de possibilidade, culminando em uma Constituição enquanto realidade social, integrando o ser e o dever-ser.

\subsection{A TEORIA DO ESTADO E DA CONSTITUIÇÃO POR JORGE MIRANDA}

Embora a obra de Jorge Miranda seja extensa e rica, cabe-nos fazer uma análise acerca da estrutura do Estado e da Constituição, para então haver um diálogo com as proposições de Heller, e permitir futuro link com a Teoria da Interconstitucionalidade.

O autor português vai explicar que o Estado deve ser visto como comunidade política - de pessoas, de homens livres. Utiliza-se da expressão "povo" como sinônimo para esta comunidade, pois a tradição (sobretudo ligada ao pensamento judaico-cristão) liga a ideia de povo como conjunto de todas as pessoas $^{29}$.

28 "[...] o Estado é uma forma organizada de vida cuja Constituição se caracteriza não só pela conduta normada e juridicamente organizada dos seus membros, mas ainda pela conduta não normada, embora normalizada, dos mesmos". Ver HELLER, Hermann. Teoria do Estado. Tradução: Lycurgo Gomes da Motta. Supervisão: João Mendes de Almeida. 1. ed. São Paulo: Editora Mestre Jou, 1968, p. 297.

29 MIRANDA, Jorge. Teoria do Estado e da Constituição. Coimbra: Coimbra Editora: 2002 , p. $267 / 268$ 
SOUZA, Matheus Figueiredo Nunes de. Direito, Estado e Democracia em Tempos de Globalização. Revista Eletrônica Direito e Política, Programa de Pós-Graduação Stricto Sensu em Ciência Jurídica da UNIVALI, Itajaí, v.12, n.3, 30 quadrimestre de 2017. Disponível em: www.univali.br/direitoepolitica - ISSN 1980-7791

No entanto, não deve haver uma confusão entre os conceitos de povo e nação, pois esta é dimensionada no domínio do espírito, da cultura, da subjetividade uma comunidade histórica de cultura (cultural que assume uma dimensão política). Pode-se definir, portanto, uma nação como aquela comunidade cultural que tem aspiração à comunidade política. ${ }^{30}$

Muito embora Miranda faça esta distinção, vai salientar que o fenômeno nacional adquire relevância político-jurídica, especificamente na medida em que o cultural condiciona o político no Estado contemporâneo. Tal relevância pode ser observada nas Constituições do Século XX, através da identificação do Estado por referência à nação a qual corresponde; através da elevação da nação a fundamento, finalidade ou limite do poder político e; através da garantia e da promoção da língua e do acesso à cultura nacional, entre outros. ${ }^{31}$

$\mathrm{Na}$ ascensão da relevância do fenômeno nacional surge a problemática das minorias e a necessidade de proteção. Antes de tudo, o que realmente está em causa é o reconhecimento aos cidadãos pertencentes a uma minoria dos mesmos direitos e das mesmas condições de exercício dos direitos dos demais cidadãos. ${ }^{32}$

Para que isso ocorra, é preciso que haja uma preservação da identidade deste grupo (nacional ou linguístico, étnico ou religioso), possibilitando assim que possa haver um desenvolvimento de forma livre. Ao avançar em suas proposições, o referido autor levantar suas considerações sobre o território como condição de existência do Estado, sua relação com o poder e o povo e também sobre o direito válido sobre este território.

Primeiramente, o território nada mais é que o espaço jurídico próprio do Estado, significando que: (I) só existe poder do Estado quando consegue impor sua autoridade sobre seu território; (II) a personalidade jurídica internacional depende da efetividade deste poder; (III) os órgãos do Estados são sediados

\footnotetext{
30 MIRANDA, Jorge. Teoria do Estado e da Constituição. Coimbra: Coimbra Editora: 2002, p. 281.

31 MIRANDA, Jorge. Teoria do Estado e da Constituição. Coimbra: Coimbra Editora: 2002, p. 284.

32 MIRANDA, Jorge. Teoria do Estado e da Constituição. Coimbra: Coimbra Editora: 2002, p. 287.
} 
SOUZA, Matheus Figueiredo Nunes de. Direito, Estado e Democracia em Tempos de Globalização. Revista Eletrônica Direito e Política, Programa de Pós-Graduação Stricto Sensu em Ciência Jurídica da UNIVALI, Itajaí, v.12, n.3, 30 quadrimestre de 2017. Disponível em: www.univali.br/direitoepolitica - ISSN 1980-7791

dentro de seu território; (IV) não existem poderes concorrentes de outros Estados dentro do território; (V) para existir poderes de outros Estados dentro do seu território é necessária sua autorização e; (VI) só dentro do território que os cidadãos tem plenitude de proteção dos seus direitos. ${ }^{33}$

Deve haver uma análise partindo tanto do âmbito interno, quanto internacional, pois somente no interior de suas fronteiras o Estado pode exercer seu poder com plenitude. As dimensões e configurações do território são assumidas na sua forma política. ${ }^{34}$

É a partir do Direito referente ao seu território que decorre o princípio da unidade jurídica - independente da forma geográfica, o território é uno, sujeito ao mesmo poder e mesmo Direito. A relação existente entre território, povo e poder se manifesta, justamente, em sua unidade, pois assim se verifica a universalidade e igualdade de direitos e deveres (previstos na Constituição e nas leis) dos cidadãos. O território é o limite efetivo para o poder político - não para o povo. ${ }^{35}$

Quanto ao poder político, é aquele que transforma uma coletividade em um povo, fazendo assim com que surja o Estado. A própria criação do poder tem juridicidade plena, pois ela estabelece relações jurídicas entre os cidadãos e se funda na ideia de direito que predomina em uma comunidade em certa circunstância. ${ }^{36}$

No entanto, o Estado não deve apenas existir, mas também deve solucionar os problemas da sociedade, fazer justiça, entre outros. Assim, trata-se de um poder de decisão - de praticar os atos pelos quais vai satisfazer as pretensões

\footnotetext{
33 MIRANDA, Jorge. Teoria do Estado e da Constituição. Coimbra: Coimbra Editora: 2002, p. 419.

34 MIRANDA, Jorge. Teoria do Estado e da Constituição. Coimbra: Coimbra Editora: 2002 , p. $420 / 421$.

35 MIRANDA, Jorge. Teoria do Estado e da Constituição. Coimbra: Coimbra Editora: 2002, p. $424 / 425$.

36 MIRANDA, Jorge. Teoria do Estado e da Constituição. Coimbra: Coimbra Editora: 2002 , p. 314.
} 
SOUZA, Matheus Figueiredo Nunes de. Direito, Estado e Democracia em Tempos de Globalização. Revista Eletrônica Direito e Política, Programa de Pós-Graduação Stricto Sensu em Ciência Jurídica da UNIVALI, Itajaí, v.12, n.3, 30 quadrimestre de 2017. Disponível em: www.univali.br/direitoepolitica - ISSN 1980-7791

generalizadas ou individualizadas de pessoas ou grupos. "É autoridade e é serviço". 37

O poder do Estado se reparte entre órgãos e agentes, se configurando em um conjunto de competências de tais órgãos. Assim, aquele poder político que transforma uma comunidade em um povo é um poder constituinte, dando ao Estado a sua primeira Constituição, e ao se repartir, entre órgãos e agentes, que vão efetivar tal poder, transforma-se em poder constituído.

Na última parte de sua obra, Jorge Miranda dedica-se ao estudo da Constituição do Estado. Segundo explica o jurisconsulto português, a Constituição possui dois aspectos, um formal e um material. Aquele se refere às disposições das normas constitucionais diante das demais normas ou do ordenamento jurídico em geral diz respeito a um poder constituinte formal como faculdade do Estado em atribuir forma e força jurídica a certas normas. O sentido material diz respeito ao estatuto jurídico político, correspondendo a um poder constituinte material como poder auto-organizativo e auto-regulatório - é através desta perspectiva que um conteúdo pode ser tornado em cerne dos princípios materiais adotados por cada Estado. ${ }^{38}$

O citado autor vai explicar que não há como conceber isoladamente estas duas dimensões da Constituição, pois se ela for vista como instrumento para institucionalização do Estado (caráter formal), ela vai carecer da (necessária) força jurídica. No entanto, se for vista apenas do ponto de vista material, careceria de uma forma adequada para desempenhar sua função organizatória da comunidade política. Assim, é da dimensão material que emerge a dimensão formal da Constituição. ${ }^{39}$

As considerações tecidas sobre a Teoria do Estado e da Constituição são de extrema importância e de contribuição ímpar, embora Jorge Miranda ainda esteja

\footnotetext{
37 MIRANDA, Jorge. Teoria do Estado e da Constituição. Coimbra: Coimbra Editora: 2002 , p. $314 / 315$.

38 MIRANDA, Jorge. Teoria do Estado e da Constituição. Coimbra: Coimbra Editora: 2002 , p. $465 / 466$.

39 MIRANDA, Jorge. Teoria do Estado e da Constituição. Coimbra: Coimbra Editora: 2002 , p. 484.
} 
SOUZA, Matheus Figueiredo Nunes de. Direito, Estado e Democracia em Tempos de Globalização. Revista Eletrônica Direito e Política, Programa de Pós-Graduação Stricto Sensu em Ciência Jurídica da UNIVALI, Itajaí, v.12, n.3, 30 quadrimestre de 2017. Disponível em: www.univali.br/direitoepolitica - ISSN 1980-7791

muito ligado à perspectiva nacional, não avançando em temas pertinentes ao constitucionalismo contemporâneo.

\subsection{TEORIA DA INTERCONSTITUCIONALIDADE}

Embora Canotilho não tenha aprofundado as questões relativas ao Estado e sua teoria (ao mesmo nível que se verifica em Heller e Miranda), teve contribuição ímpar para o Constitucionalismo Contemporâneo, com estudos de solidez sem igual, sendo o precursor do Dirigismo Constitucional, e, posteriormente, "matando" sua criação, em virtude do não cumprimento do triângulo dialético, e promovendo novas incursões teóricas.

Obras como "Constituição Dirigente e Vinculação do Legislador" e "Direito Constitucional e Teoria da Constituição" são de extrema importância para a compreensão das questões relativas à Carta Constitucional. Porém, ao observar o panorama social e político na atualidade, Canotilho verificou que as proposições anteriormente feitas já não davam conta de responder todas as questões. Assim, ao abordar a Teoria da Constituição como uma Rede de Teorias, vai fazer suas primeiras proposições voltadas para a Teoria da Interconstitucionalidade.

O citado autor explica que, nos dias atuais, não há como realizar um estudo da teoria da Constituição dissociado da Teoria da Interconstitucionalidade, pois esta tese visa estudar as relações de concorrência, convergência, justaposição e conflito de várias constituições e de vários poderes constituintes no mesmo espaço político. ${ }^{40}$

Explica, ainda, que sua Teoria da Interconstitucionalidade é inovadora nos seguintes pontos: (I) na existência de uma rede de constituições de estados soberanos; (II) nas turbulências que podem ocorrer na organização constitucional por demais organizações políticas; (III) a recombinação das dimensões constitucionais clássicas através de sistemas organizativos de grandeza superior; (IV) uma coerência constitucional frente à diversidade de

40 CANOTILHO, J. J. Gomes. Direito Constitucional e Teoria da Constituição. 7. ed., 16 reimp. Coimbra: Editora Almedina, 2003, p. 1425. 
SOUZA, Matheus Figueiredo Nunes de. Direito, Estado e Democracia em Tempos de Globalização. Revista Eletrônica Direito e Política, Programa de Pós-Graduação Stricto Sensu em Ciência Jurídica da UNIVALI, Itajaí, v.12, n.3, 30 quadrimestre de 2017. Disponível em: www.univali.br/direitoepolitica - ISSN 1980-7791

constituições na rede; (V) criação de um esquema jurídico político que possua um grau suficiente de confiança condicionada entre as várias constituições da rede interconstitucional. ${ }^{41}$

Conforme salienta, a Teoria da Interconstitucionalidade vem trabalhar no sentido da fenomenologia jurídica e política de um pluralismo de ordenamentos e normatividades, verificando a articulação entre as Constituições e a afirmação de poderes constituintes com fontes de legitimidades diversas. No entanto, é importante dizer que, por mais que as Constituições tenham perdido certo protagonismo, elas ainda possuem suas identidades mesmo em contato com outras Cartas Constitucionais. ${ }^{42}$

A comunicação que é gerada por esta rede de interconstitucionalidade é assentada em princípios comuns que se assentam em uma ideia de culturalidade - tanto da Constituição quanto do Estado Constitucional. ${ }^{43} \mathrm{~A}$ ideia proposta se alinha com os pensamentos de Peter Häberle (de pensar a Constituição como cultura), pois consegue combater posições que ainda são defendidas, tais como o positivismo, formalismo, estatismo. ${ }^{44}$

Exposto isso, Canotilho começa a fazer uma análise do dirigismo constitucional e sua crise. Nesse sentido, vai explicar que a Carta Constitucional deixava de ser uma lei para tornar-se uma "bíblia de promessas". ${ }^{45}$ Outro problema encontrado pela Constituição Dirigente era sua falta de imediaticidade atuativa e concretizável das normas e princípios constitucionais, através de programas e

41 CANOTILHO, J. J. Gomes. Direito Constitucional e Teoria da Constituição. 7. ed., 16 reimp. Coimbra: Editora Almedina, 2003, p. 1425.

42 CANOTIlHo, J. J. Gomes. Direito Constitucional e Teoria da Constituição. 7. ed., 16 reimp. Coimbra: Editora Almedina, 2003, p. 1425/1426.

43 CANOTIlHO, J. J. Gomes. Direito Constitucional e Teoria da Constituição. 7. ed., 16 reimp. Coimbra: Editora Almedina, 2003, p. 1427/1428.

44 CANOTILHO, J. J. Gomes. "Brancosos" e Interconstitucionalidade: itinerários dos discursos sobre a historicidade constitucional. 2. ed. Reimpressão. Coimbra: Editora Almedina, 2012, p. 264.

45 CANOTILHO, J. J. Gomes. "Brancosos" e Interconstitucionalidade: itinerários dos discursos sobre a historicidade constitucional. 2. ed. Reimpressão. Coimbra: Editora Almedina, 2012, p. 31. 
SOUZA, Matheus Figueiredo Nunes de. Direito, Estado e Democracia em Tempos de Globalização. Revista Eletrônica Direito e Política, Programa de Pós-Graduação Stricto Sensu em Ciência Jurídica da UNIVALI, Itajaí, v.12, n.3, 30 quadrimestre de 2017. Disponível em: www.univali.br/direitoepolitica - ISSN 1980-7791

diretivas. ${ }^{46}$ A Constituição Dirigente nada mais fazia que delegar tarefas ao Estado, além de buscar estatizar o mundo e a vida. ${ }^{47}$

Canotilho trata de dez problemas que vieram com a Pós-Modernidade, os quais a Constituição e o Estado dirigente se deparam, são eles: (1) problemas de inclusão; (2) problemas de referência; (3) problemas de reflexividade; (4) problemas de universalização; (5) problemas de materialização do direito; (6) problemas de reinvenção do território; (7) problemas de tragédia; (8) problemas de fundamentação; (9) problemas de simbolização e (10) problemas de referência. Dentre estes, merecem destaque os problemas de inclusão, materialização do direito e de referência. ${ }^{48}$

Acerca dos problemas de inclusão, a Constituição outorgou para si a pretensão de ser um estatuto político e jurídico. Porém, no patamar político, existe certa rebeldia a uma normativização legalista, enquanto que no patamar jurídico tornou-se um produto das concepções voluntaristas do direito e do sujeito, deixando de lado sua autorreferencialidade e auto-organização. ${ }^{49}$

No que tange à materialização do direito, ao assumir um caráter de superdiscurso social, com uma concepção juridicista, purista e piramidal, a Constituição deixou um espectro muito amplo acerca dos direitos, em uma tentativa de "abraçar o mundo" - mesmo quando tinha assento no próprio texto.

46 CANOTILHO, J. J. Gomes. "Brancosos" e Interconstitucionalidade: itinerários dos discursos sobre a historicidade constitucional. 2. ed. Reimpressão. Coimbra: Editora Almedina, 2012 , p. 32.

47 CANOTILHO, J. J. Gomes. "Brancosos" e Interconstitucionalidade: itinerários dos discursos sobre a historicidade constitucional. 2. ed. Reimpressão. Coimbra: Editora Almedina, 2012, p. 113.

48 CANOTILHO, J. J. Gomes. "Brancosos" e Interconstitucionalidade: itinerários dos discursos sobre a historicidade constitucional. 2. ed. Reimpressão. Coimbra: Editora Almedina, 2012, p. 216-221.

49 CANOTILHO, J. J. Gomes. "Brancosos" e Interconstitucionalidade: itinerários dos discursos sobre a historicidade constitucional. 2. ed. Reimpressão. Coimbra: Editora Almedina, 2012, p. 216. 
SOUZA, Matheus Figueiredo Nunes de. Direito, Estado e Democracia em Tempos de Globalização. Revista Eletrônica Direito e Política, Programa de Pós-Graduação Stricto Sensu em Ciência Jurídica da UNIVALI, Itajaí, v.12, n.3, 30 quadrimestre de 2017. Disponível em: www.univali.br/direitoepolitica - ISSN 1980-7791

Por outro lado, encontrava-se óbice, pois as normas constitucionais dificilmente eram contextualizadas, alheando-se da mudança e da inovação jurídica. ${ }^{50}$

Sobre as problemáticas de referência, é necessário destacar que uma das aspirações da Constituição Programática, direta ou indiretamente, era alcançar o ponto ômega da modernidade política, por meio de uma organização voluntária das sociedades. No entanto, não há como negar que as sociedades atuais possuem um caráter eminentemente pluralista e se estruturam nos termos de sua complexidade. Essa complexidade se fundamenta, antes de tudo, na sua auto-organização - diferentemente da intenção construtivista da política. ${ }^{51}$

Diante disso, verifica-se que a vivência apenas partindo de uma perspectiva interna não é mais suficiente, pois dentro de um mesmo espaço político existem várias organizações políticas, existindo vários ordenamentos jurídicos entrelaçados, uns influenciando os outros, fazendo assim com que o constitucionalismo seja elevado a nível global ${ }^{52}$ e o Estado seja reduzido a um simples herói do local.

\section{A DEMOCRACIA NA ERA DA GLOBALIZAÇÃO}

Observando as teorias do Estado e da Constituição aqui trabalhadas, verifica-se que as proposições de Hermann Heller e Jorge Miranda, embora de grande relevância, não conseguem contribuir de forma profunda para a compreensão do papel do Direito, do Estado e da Democracia em tempos de globalização. Ambos os autores ainda atribuem ao Estado e à Constituição um papel central na

\footnotetext{
50 CANOTILHO, J. J. Gomes. "Brancosos" e Interconstitucionalidade: itinerários dos discursos sobre a historicidade constitucional. 2. ed. Reimpressão. Coimbra: Editora Almedina, 2012 , p. $219 / 220$.

51 CANOTILHO, J. J. Gomes. "Brancosos" e Interconstitucionalidade: itinerários dos discursos sobre a historicidade constitucional. 2. ed. Reimpressão. Coimbra: Editora Almedina, 2012, p. 221.

52 Embora Canotilho proponha uma rede interconstitucional que eleva o constitucionalismo a nível global, principalmente através do estabelecimento de uma Constituição Europeia, deixa de abordar mais especificamente como aconteceria esse processo de elevação. Questiona-se aqui, primeiramente, se conceitos clássicos, tais como poder constituinte, Assembleia, vigência e validade, conseguiriam se manter frente ao caráter global; em segundo, se não estaria apenas elevando mais um nível da pirâmide de Kelsen?
} 
SOUZA, Matheus Figueiredo Nunes de. Direito, Estado e Democracia em Tempos de Globalização. Revista Eletrônica Direito e Política, Programa de Pós-Graduação Stricto Sensu em Ciência Jurídica da UNIVALI, Itajaí, v.12, n.3, 30 quadrimestre de 2017. Disponível em: www.univali.br/direitoepolitica - ISSN 1980-7791

questão do poder e da produção normativa, reproduzindo uma visão de relação vertical na produção da norma.

Porém, com uma Sociedade cada vez mais interligada em um viés comunicativo, a emergência de demais atores nos planos internacional e transnacional não pode ser relegada a um papel secundário, devendo o Estado e a Democracia enfrentarem as complexidades sociais. Mas o que é democracia?

Conforme vai explicar Bobbio, a democracia é vista como poder em público, pois visa transmitir a essência de que as tomadas de decisões devem ser feitas de forma transparente pelos governantes, para que então os governados possam ver como elas se dão e como são formadas. ${ }^{53}$

Já Kelsen vai salientar que Democracia quer dizer que a vontade representada na ordem jurídica do Estado é a mesma que a vontade dos sujeitos que participam dela. Ademais, é considerado politicamente livre aquele indivíduo que participa da criação de uma ordem jurídica. ${ }^{54}$

Outra concepção é aquela proposta por Jürgen Habermas, expressada através do princípio fundamental da democracia - que se desdobra em (I) princípio do discurso e (II) forma jurídica. O princípio do discurso exige que só sejam aceitos como corretas aquelas normas que possam obter o assentamento de todos os afetados em um discurso racional, enquanto a forma jurídica acontece através da institucionalização jurídica de condições para um exercício discursivo da autonomia política. ${ }^{55}$

Porém, o referido autor tem repensando alguns pontos acerca da democracia, principalmente no panorama pós-nacional e com as influências existentes em um cenário de globalização - logo no pós-guerra, o sistema Bretton Woods, assimilado ao FMI e o Banco Mundial introduziram regras de um comércio

53 BOBBIO, Norberto. Teoria Geral da Política: a filosofia e as lições dos clássicos. Organizado por Michelangelo Bovero; tradução Daniela Beccaccia Versiani. Rio de Janeiro: Campus, 2000, p. 386.

54 KELSEN, Hans. Teoria Geral do Direito e do Estado. Tradução Luís Carlos Borges. 3. ed. São Paulo: Martins Fontes, 1998, p. 408/409.

55 HABERMAS, Jürgen. Direito e Democracia: entre facticidade e validade. vol. 1. Tradução: Flávio Beno Siebeneichler. Rio de Janeiro: Tempo Brasileiro, 1997, p. 158. 
SOUZA, Matheus Figueiredo Nunes de. Direito, Estado e Democracia em Tempos de Globalização. Revista Eletrônica Direito e Política, Programa de Pós-Graduação Stricto Sensu em Ciência Jurídica da UNIVALI, Itajaí, v.12, n.3, 30 quadrimestre de 2017. Disponível em: www.univali.br/direitoepolitica - ISSN 1980-7791

mundial liberalizado, o que alterou e prejudicou a autonomia e capacidade da ação político-econômica dos atores estatais (lembra-se também o surgimento das corporações multinacionais!). ${ }^{56}$

Percebe-se que, de fato, a sociedade é complexa e cheia de riscos, com ambientes assimétricos, razão pela qual a democracia em seu sentido tradicional é insuficiente para enfrentar os novos anseios sociais. A complexidade do mundo, a globalização e a heterogeneidade social tem praticamente reduzido a democracia apenas a um procedimento. ${ }^{57}$ Assim, o século XXI, visto por uma ótica globalizatória, faz com que procedamos a um exercício de reflexão, ao questionar quais são os fundamentos, instituições e contextos sociais da democracia. ${ }^{58}$

Caso contrário, estaremos diante de um governo tecnocrata - extremamente decisório, instantâneo e sem muitas cerimônias, que tem se mostrado um fenômeno novo. Isso faria com que a Democracia fosse destruída (algo, no mínimo, paradoxal, sendo a democracia a causa de sua possibilidade/impossibilidade). ${ }^{59}$

Uma proposta feita por Jean-Arnaud, que se adéqua as novas tendências é o poder em partilha, onde a sociedade civil é redescoberta como ator integral. A emergência de novos atores no cenário global é evidente, onde, nesse sentido, a legitimidade dos movimentos da sociedade civil provém de um reconhecimento por parte das instituições ou programas ligados às Nações Unidas. Exemplo disso são as ONG's, que até ganharam status consultivo da ONU. ${ }^{6}$

56 HABERMAS, Jürgen. A Constelação Pós-Nacional: ensaios políticos. Tradução de Márcio Seligmann Silva. São Paulo: Littera Mundi, 2001, p. 99/100.

57 CRUZ, Paulo Márcio; FERRER, Gabriel Real. Los Nuevos Escenarios Transnacionales y la Democracia Asimétrica. Jurídicas, Manizales, v. 7 (2). p. 13-41, Julio-Deciembre, 2010, p. 15

58 CRUZ, Paulo Márcio; FERRER, Gabriel Real. Los Nuevos Escenarios Transnacionales y la Democracia Asimétrica. Jurídicas, Manizales, v. 7 (2). p. 13-41, Julio-Deciembre, 2010, p. 18.

59 STAFFEN, Márcio Ricardo. A Redução do Estado Constitucional Nacional e a Ascensão do Direito Global! Há espaço para os Juizados Especiais Federais? In: STAFFEN, Márcio Ricardo; MORAIS DA ROSA, A. Direito Global: Transnacionalidade e Globalização Jurídica. Itajaí: UNIVALI, 2013, p. 79.

60 JEAN-ARNAUD, Andre. Governar sem Fronteiras: entre globalização e pós-globalização. Rio de Janeiro: Editora Lumen Juris, 2007, p. 224; 232. 
SOUZA, Matheus Figueiredo Nunes de. Direito, Estado e Democracia em Tempos de Globalização. Revista Eletrônica Direito e Política, Programa de Pós-Graduação Stricto Sensu em Ciência Jurídica da UNIVALI, Itajaí, v.12, n.3, 30 quadrimestre de 2017. Disponível em: www.univali.br/direitoepolitica - ISSN 1980-7791

No mesmo norte, a democracia participativa enquanto participação nos processos decisórios (que levam, posteriormente, à decisões definitivas) permite uma democracia mais pluralista, à diferença do consenso moderno, sobre a unanimidade (consenso) - o que levaria a um pseudo-pluralismo. ${ }^{61}$

Aliado a isso, é necessário uma posição de transparência enquanto pretensão jurídica global, pois o acesso à informação acaba por romper com os limites geográficos e políticos da soberania do Estado, bem como com as estruturas de poder fortemente verticalizadas e burocráticas. ${ }^{62}$ Esta rede (complexa) entrelaçada de níveis múltiplos, oriundo da globalização jurídica e do transnacionalismo, clama pela ciência dos envolvidos e os destinatários do ato. ${ }^{63}$

Portanto, em tempos de globalização, verifica-se que a democracia é remodelada, a fim de que possa responder aos anseios sociais, assumindo um caráter participativo, através de referendos, consultas populares, assembleias de políticas públicas, controvérsias de consenso, gestão municipal participativa, entre outros. ${ }^{64} \mathrm{O}$ caráter de participação e partilha do poder vai se delineando, sendo legitimado através de uma pretensão de transparência dos atos, desde o local até o global.

61 CRUZ, Paulo Márcio; FERRER, Gabriel Real. Los Nuevos Escenarios Transnacionales y la Democracia Asimétrica. Jurídicas, Manizales, v. 7 (2). p. 13-41, Julio-Deciembre, 2010, p. $27 / 28$.

62 STAFFEN, Márcio Ricardo. Globalismo Jurídico. Peru: EGACAL - Escuela de Altos Estudios Jurídicos, 2015, p. 63.

63 STAFFEN, Márcio Ricardo; OLIVIERO, Maurizio. Transparência enquanto Pretensão Jurídica Global. Revista de Direito Administrativo e Constitucional, ano 15, n. 61, p. 71-91, jul./set., 2015, p. 86

64 CRUZ, Paulo Márcio. Democracia e Pós-Modernidade. Pensar, Fortaleza, v. 13, n. 2, p. $256-$ 271, jul./dez. 2008, p. 269. 
SOUZA, Matheus Figueiredo Nunes de. Direito, Estado e Democracia em Tempos de Globalização. Revista Eletrônica Direito e Política, Programa de Pós-Graduação Stricto Sensu em Ciência Jurídica da UNIVALI, Itajaí, v.12, n.3, 30 quadrimestre de 2017. Disponível em: www.univali.br/direitoepolitica - ISSN 1980-7791

\section{CONSIDERAÇÕES FINAIS}

Ao longo deste trabalho restou evidente que as concepções clássicas de Direito, Estado, Constituição e Democracia não mais conseguem lidar com a complexidade da sociedade e as interações em níveis múltiplos, ainda mais após a intensificação do processo de globalização.

A perspectiva de um fechamento constitucional do Estado não consegue mais ser sustentada, visto que poderia levar a um "autismo jurídico"; a soberania passa a ser mitigada e observa-se um fenômeno de entrelaçamento entre os ordenamentos jurídicos existentes dentro de um mesmo espaço político, algo cada vez mais observável em uma teia de complexidade.

O fenômeno jurídico da policontexturalidade é cristalino, pois o Direito, que antes era produto exclusivo do Estado, passa a ser produzido em contextos sociais, econômicos, em âmbito internacional, supranacional...

O Estado e sua Constituição não mais conseguem responder aos problemas jurídicos que se apresentam igualmente a mais de um ordenamento legal. Enquanto, em tempos idos, o Estado fazia uso da sua força e da soberania dentro do seu território, agora só levaria a uma falta de comunicação, podendo, muitas vezes, acabar negando a existência do Outro.

Já a Democracia vista, unicamente, através de uma ótica representativa, também se torna insuficiente, pois com a evolução social e o surgimento de demais atores, novas organizações têm promovido a inserção da sociedade civil nos processos decisórios - incluindo no discurso todos aqueles que podem ser afetados, aflorando uma perspectiva participativa, bem como acaba conferindo um prisma de transparência e maior legitimidade.

Portanto, o Direito enquanto fenômeno policontextural permite que a existência e sustentação de uma rede de interconstitucionalidade, que por sua vez fortifica uma democracia participativa que almeja a transparência como pretensão jurídica global, através da possibilidade de diálogo de vários ordenamentos jurídicos existentes em um mesmo espaço político. 
SOUZA, Matheus Figueiredo Nunes de. Direito, Estado e Democracia em Tempos de Globalização. Revista Eletrônica Direito e Política, Programa de Pós-Graduação Stricto Sensu em Ciência Jurídica da UNIVALI, Itajaí, v.12, n.3, 30 quadrimestre de 2017. Disponível em: www.univali.br/direitoepolitica - ISSN 1980-7791

\section{REFERÊNCIAS DAS FONTES CITADAS}

ABBAGNANO, Nicola. Dicionário de Filosofia. Tradução da 10 edição brasileira coordenada e revista por Alfredo Bossi; revisão da tradução e tradução dos novos textos Ivone Castilho Benedetti. 5. ed. São Paulo: Martins Fontes, 2007.

BOBBIO, Norberto; MATTEUCCI, Nicola; PASQUINO, Gianfranco. Dicionário de Política. Tradução Carmen C. Varriale et. al.; coord. trad. João Ferreira; rev. geral João Ferreira e Luis Guerreiro Pinto Cacais. 1. ed. Brasília: Editora Universidade de Brasília, 1998.

- Teoria Geral da Política: a filosofia e as lições dos clássicos. Organizado por Michelangelo Bovero; tradução Daniela Beccaccia Versiani. Rio de Janeiro: Campus, 2000.

CANOTILHO, J. J. Gomes. Direito Constitucional e Teoria da Constituição. 7. ed., 16 reimp. Coimbra: Editora Almedina, 2003.

"Brancosos" e Interconstitucionalidade: itinerários dos discursos sobre a historicidade constitucional. 2. ed. Reimpressão. Coimbra: Editora Almedina, 2012.

CRUZ, Paulo Márcio. Democracia e Pós-Modernidade. Pensar, Fortaleza, v. 13, n. 2, p. 256-271, jul./dez. 2008.

; FERRER, Gabriel Real. Los Nuevos Escenarios Transnacionales y la Democracia Asimétrica. Jurídicas, Manizales, v. 7 (2). p. 13-41, JulioDeciembre, 2010.

HABERMAS, Jürgen. Direito e Democracia: entre facticidade e validade. vol. 1. Tradução: Flávio Beno Siebeneichler. Rio de Janeiro: Tempo Brasileiro, 1997.

A Constelação Pós-Nacional: ensaios políticos. Tradução de Márcio Seligmann Silva. São Paulo: Littera Mundi, 2001.

HART, H. L. A. O Conceito de Direito. Tradução: A. Ribeiro Mendes. 3. ed. Lisboa: Fundação Calouste Gulbenkian, 2001.

HELLER, Hermann. Teoria do Estado. Tradução: Lycurgo Gomes da Motta. Supervisão: João Mendes de Almeida. 1. ed. São Paulo: Editora Mestre Jou, 1968.

JEAN-ARNAUD, Andre. Governar sem Fronteiras: entre globalização e pósglobalização. Rio de Janeiro: Editora Lumen Juris, 2007.

KELSEN, Hans. Teoria Pura do Direito. Tradução: João Baptista Machado. 6. ed. São Paulo: Martins Fontes, 1998.

Teoria Geral do Direito e do Estado. Tradução de Luís Carlos Borges. 3. ed. São Paulo: Martins Fontes, 1998. 
SOUZA, Matheus Figueiredo Nunes de. Direito, Estado e Democracia em Tempos de Globalização. Revista Eletrônica Direito e Política, Programa de Pós-Graduação Stricto Sensu em Ciência Jurídica da UNIVALI, Itajaí, v.12, n.3, 30 quadrimestre de 2017. Disponível em: www.univali.br/direitoepolitica - ISSN 1980-7791

LUHMANN, Niklas. La sociedad de La sociedad. Traducción: Javier Torres Nafarrate. Ciudad de México: edición Heder, 2006.

MIRANDA, Jorge. Teoria do Estado e da Constituição. Coimbra: Coimbra Editora: 2002.

SCOTT, Craig. "Transnational" Law as a Proto-concept: Three Conceptions. CLPE Research Paper 33/2009. vol. 05, no. 06.

STAFFEN, Márcio Ricardo. A Redução do Estado Constitucional Nacional e a Ascensão do Direito Global! Há espaço para os Juizados Especiais Federais? In: STAFFEN, Márcio Ricardo; MORAIS DA ROSA, A. Direito Global: Transnacionalidade e Globalização Jurídica. Itajaí: UNIVALI, 2013. Jurídicos, 2015.

Globalismo Jurídico. Peru: EGACAL - Escuela de Altos Estudios ; ZAMBAM, Neuro. Direito Global e Desigualdades: Um Estudo a partir do "Direito dos Povos" de John Rawls. Revista Eletrônica do Curso de Direito da UFSM. v. 10, n. 1, 2015.

; OLIVIERO, Maurizio. Transparência enquanto Pretensão Jurídica Global. Revista de Direito Administrativo e Constitucional, ano 15, n. 61, p. 71-91, jul./set., 2015.

TEUBNER, Gunther. The King's Many Bodies: The Self-Deconstruction of Law's Hierarchy. Law and Society Review. Volume 31, Number 4, 1997.

Direito, Sistema e Policontexturalidade. Tradução: Jürgen Volker Dittbrener... (et. al.). Piracicaba: editor Unimep, 2005.

TONET, Fernando. Reconfigurações do Constitucionalismo: evolução e modelos constitucionais sistêmicos na pós-modernidade. $1^{a}$ ed. Rio de Janeiro, Lumen Juris, 2013.

Submetido em: setembro de 2017

Aprovado em: outubro de 2017 